\title{
Caminhos da sustentabilidade para o cinema brasileiro*
}

Maria Cristina Attayde

\section{Introdução}

O cinema brasileiro, muitas vezes objeto de discussões polêmicas e posicionamentos divergentes, é um tema que sempre desperta interesse na maior parte das pessoas. Quando se fala, por exemplo, em isenções fiscais com o intuito de financiar o cinema nacional, as reações são, na maioria das vezes, de perplexidade e indignação. Como pode haver esse tipo de incentivo num país em que nem as prioridades básicas da população sequer foram atingidas satisfatoriamente? É legítimo recursos públicos serem aplicados em produções culturais cujo público-alvo tem um alto poder aquisitivo, em comparação com a maioria da população brasileira? Além disso, seria o cinema o guardião exclusivo da identidade cultural do País, de modo a justificar tal benefício? Sendo assim, muitas vezes, questiona-se o motivo pelo qual o cinema, ao contrário de outros setores, não necessita lutar por ganhos de competitividade, perpetuando-se a dependência aos incentivos fiscais. 
O cinema, independentemente $\mathrm{da}$ forma como é veiculado, seja via tela de exibição ou mídia eletrônica, é um importante meio de auto-identificação de uma sociedade. Porém, quando esse espaço de crítica e autoconhecimento é ocupado, de forma dominante e, por que não dizer, avassaladora, por produções estrangeiras, notadamente a norte-americana, estas passam a ser uma das principais referências da formação cultural de um povo, particularmente dos mais jovens. É claro que esse predomínio da indústria cinematográfica americana, não apenas no Brasil, como em nível mundial, é resultado da atuação de empresas de entretenimento focadas na eficiência e na conquista de mercados. No entanto, a questão é: esses espaços estratégicos devem ser ocupados obedecendo-se estritamente a uma ordem de mercado ou deve-se intervir de alguma forma não apenas para reconquistar espaços do ponto de vista econômico, mas também para garantir a diversidade cultural? É legítima essa intervenção em termos de política de Estado, como ocorre em vários países, notadamente os europeus?

Quando se fala em sustentabilidade da atividade cinematográfica no Brasil, temse em mente a consolidação desse setor em termos industriais, com a conseqüente ampliação de ocupação da parcela no mercado brasileiro, que, atualmente, está em torno de $15 \%$. Isso implica a gradual independência em relação aos incentivos fiscais, de forma que o setor privado se sinta estimulado a investir cada vez mais recursos próprios não apenas como forma de estratégia de marketing cultural, isto é, atrelar a sua marca a um produto cultural de maneira a usufruir de uma mídia espontânea, mas, também, como fonte financiadora de uma atividade atrativa em termos financeiros.
Isso não quer dizer que outras formas de financiamento do cinema brasileiro devam ser abolidas, a exemplo do fomento direto, que pressupõe a disponibilização de recursos orçamentários do Ministério da Cultura, no intuito de estimular produções de importância cultural a serem avaliadas sob critérios de política pública.

A questão da sustentabilidade do cinema brasileiro deve ser vista não apenas por critérios puramente mercadológicos, mas também por critérios de políticas públicas. Por um lado, é importante que essa atividade aumente seu potencial industrial para financiar-se, o que permitirá a redução gradativa da dependência em relação aos incentivos fiscais. Ademais, isso tornará a atividade cinematográfica menos vulnerável a decisões arbitrárias, como as ocorridas no governo Collor, ocasião em que foi extinta a Embrafilme e o próprio Ministério da Cultura, o que fez cair a participação do filme nacional, no mercado exibidor, ao seu nível mais baixo em 1992, com um índice de $0,05 \%{ }^{1}$. Por outro lado, deve-se considerar que o cinema é uma atividade diferenciada, pois representa uma forma de manifestação cultural de forte influência sobre comportamentos e valores sociais. Sendo assim, formas de financiamento, como o fomento direto, são importantes, assim como medidas regulatórias capazes de aumentar o acesso da população a essas obras.

Para se avaliarem as dificuldades da atividade cinematográfica no Brasil, à luz da definição de sustentabilidade para o setor, o artigo subdivide-se nos seguintes tópicos:

- a estrutura da cadeia produtiva e seus pontos de estrangulamento;

- as diferenças de remuneração entre os elos da cadeia produtiva, as distorções da estrutura tributária que onera em 
demasia o setor e a legislação de incentivo ao cinema, apontando as distorções que contribuem para a perpetuação da dependência a isenções fiscais;

- a possibilidade da parceria TV/ cinema a partir da discussão de uma lei geral de comunicação de massa;

- propostas que contribuirão para a sustentabilidade do setor: mudanças na legislação, em particular, a Lei do Audiovisual; mudanças na estrutura tributária e medidas de caráter regulatório a fim de garantir a exibição de filmes nacionais na grade televisiva.

\section{A cadeia produtiva}

Resumidamente, o audiovisual, incluindo o cinema, integra uma cadeia produtiva que se constitui das seguintes etapas:

1) Desenvolvimento: o produtor adquire direitos sobre o roteiro original, contata parcerias artísticas e financeiras e estima o orçamento para a produção (filme ou programa de TV);

2) Produção: a) pré-produção: reunião de recursos humanos (equipe técnica, elenco), técnicos (equipamentos, seleção de locações) e financeiros; b) produção propriamente dita: tomadas de cena; c) pós-produção: edição, trilha sonora, efeitos especiais, reprodução de cópias, etc.;

3) Distribuição: a) divulgação e venda de filmes a exibidores pela empresa de distribuição; b) programas de TV: é "empacotado" e transmitido aos telespectadores por meio de canais de TV, internet, etc. Algumas vezes os contratos de distribuição são feitos antes do término da produção;

4) Exibição ou transmissão: a) exibição nas telas de cinema e televisão; lançamentos em vídeo/DVD. No caso de exploração de uma obra cinematográfica, esta perpassa pelas seguintes janelas de exibição, de forma sucessiva: salas de exibição, vídeo/DVD, TV fechada e TV aberta. A sala de exibição é considerada a janela estratégica, pois é com base no desempenho nas salas de cinema que será definido o valor do licenciamento do filme nos demais meios de exibição.

A cadeia produtiva é formada, basicamente, de empresários ligados, direta ou indiretamente, a audiovisual, produtores de cinema, televisão, vídeo, multimídia,

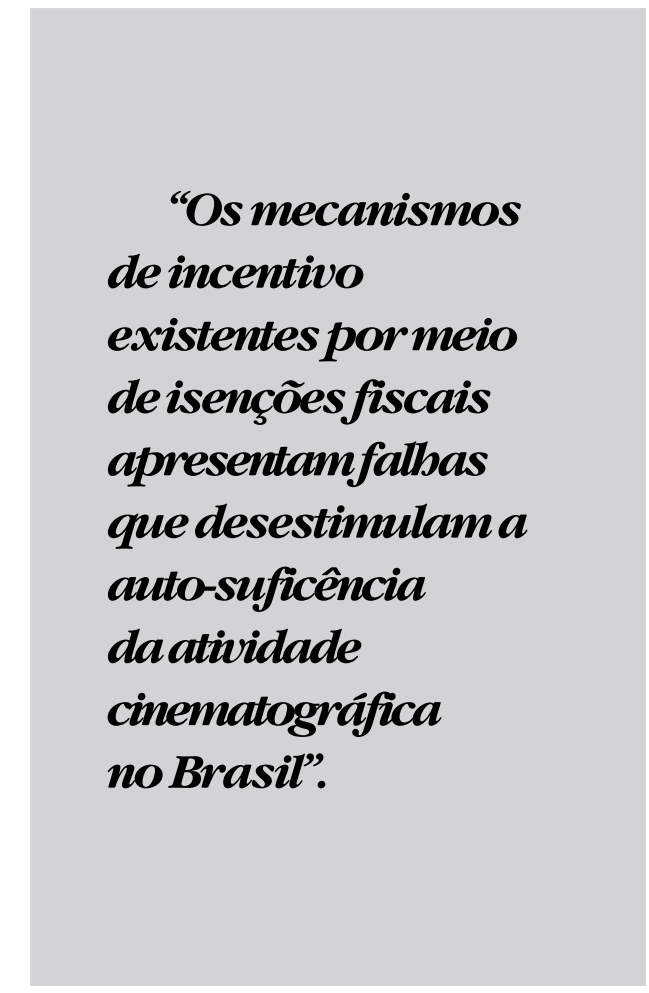

distribuidores, exibidores, diretores, roteiristas, trabalhadores na produção de equipamentos, técnicos de cinema, televisão, entre outros. Especificamente com relação ao cinema, este é considerado um investimento de alto risco ${ }^{2}$, pois são produtos com custos fixos e sunk costs $^{3}$ elevados.

Atualmente, tornou-se consenso dizer que o grande gargalo da cadeia produtiva 
é a distribuição, tendo em vista que boa parte de filmes brasileiros não tem vinculação com as grandes distribuidoras estrangeiras, o que dificulta o acesso ao mercado. Segundo a análise do Relatório de Auditoria do Tribunal de Contas da União relativo ao Processo $\mathrm{n}^{\circ}$ 005.628/ 2004-0, no que diz respeito à utilização de leis de incentivo, constatou-se grande volume de obras concluídas, porém sem veiculação no exercício de 2003 , ou seja, $30 \%$. Em 2003, foram finalizados e não comercializados (não veiculados) 22 filmes e finalizados e lançados ou programados 45 filmes veiculados a uma distribuidora.

Verifica-se (vide Tabela 1) que as majors, ou seja, as grandes distribuidoras norteamericanas (Warner, Columbia, Fox, UIP, Buena Vista), detêm a maior parcela do mercado de distribuição no Brasil, tanto em relação a público quanto a renda, o que caracteriza um mercado altamente concentrado e permite o predomínio de filmes estrangeiros lançados pelas majors no mercado brasileiro, conforme a Tabela 2 . Isso porque essas produções já chegam com uma estratégia de marketing pronta (por exemplo, cartazes e trailers), o que resulta em despesas de comercialização menores em relação a filmes brasileiros. Além disso, a renúncia fiscal prevista no art. $3^{\circ}$ da Lei do Audiovisual permite às majors tornarem-se sócias do filme, além de adquirirem direitos de distribuição. Há, assim, dupla remuneração: como distribuidora e como sócia cuja remuneração representa parte da renda líquida destinada aos produtores, sendo, por isso, uma opção muito mais lucrativa. Como conseqüência, os filmes brasileiros não produzidos sob o amparo do art. $3^{\circ} \mathrm{da}$ Lei do Audiovisual têm acesso mais limitado às redes de distribuição e, muitas vezes, não conseguem chegar às salas de exibição.

Tabela 1: Market share das distribuidoras - 2004

\begin{tabular}{l|c|c|c|c}
\hline & Público & \% & Renda (R\$) & \% \\
\hline Warner & 25.455 .773 & 22,2 & 168.938 .320 & 22,1 \\
\hline Columbia & 22.975 .413 & 20,1 & 148.781 .836 & 19,4 \\
\hline Fox & 21.534 .798 & 18,8 & 142.684 .345 & 18,6 \\
\hline UIP & 17.521 .729 & 15,3 & 119.037 .810 & 15,5 \\
\hline Buena Vista & 14.430 .785 & 12,6 & 98.907 .577 & 12,9 \\
\hline Lumière & 6.049 .713 & 5,3 & 40.401 .790 & 5,3 \\
\hline Europa/MAM & 3.629 .749 & 3,2 & 26.638 .743 & 3,5 \\
\hline Playarte & 2.400 .113 & 2,1 & 16.491 .769 & 2,2 \\
\hline Art Films & 409.272 & 0,4 & 2.995 .738 & 0,4 \\
\hline Riofilme & 115.242 & 0,1 & 701.856 & 0,1 \\
\hline Total & $\mathbf{1 1 4 . 5 2 2 . 5 8 7}$ & $\mathbf{1 0 0}$ & $\mathbf{7 6 5 . 5 7 9 . 7 8 4}$ & $\mathbf{1 0 0}$ \\
\hline
\end{tabular}

Fonte: Filme B 
Tabela 2: Market share de filmes estrangeiros e nacionais

\begin{tabular}{l|c|c|c|c}
\hline & Público $(\mathbf{e m ~ m i l )}$ & $\%$ & Títulos lançados & $\%$ \\
\hline Filmes estrangeiros lançados pelas majors & 86.324 .122 & 76 & 116 & 31 \\
\hline Filmes estrangeiros de arte e independentes & 11.998 .419 & 10 & 135 & 45 \\
\hline Filmes nacionais & 16.410 .957 & 14 & 51 & 17 \\
\hline Total & $\mathbf{1 1 4 . 7 3 3 . 4 9 8}$ & $\mathbf{1 0 0}$ & $\mathbf{3 0 2}$ & $\mathbf{1 0 0}$ \\
\hline
\end{tabular}

Fonte: Filme B

\section{O ciclo vicioso da dependência aos incentivos fiscais}

\section{A legislação de incentivo ao cinema}

Atualmente, as leis de incentivo fiscal que financiam produções cinematográficas são:

Lei do Audiovisual (Lei $\mathrm{n}^{\circ}$ 8.685, de 20.7.1993): determina que os contribuintes que investirem em audiovisual, nos termos da lei, podem beneficiar-se de três formas: a) dedução do imposto de renda devido, correspondente às quantias referentes aos investimentos feitos na produção de obra audiovisual cinematográfica brasileira de produção independente, mediante aquisição de quotas representativas de direito de comercialização (art. $1^{\circ}$, caput); b) os projetos específicos da área audiovisual, cinematográfica de exibição, distribuição e infra-estrutura técnica apresentados por empresa brasileira de capital nacional poderão ser credenciados pelos Ministérios da Fazenda e da Cultura para fruição dos incentivos fiscais $\left(\operatorname{art.} 1^{\circ}, \int 5^{\circ}\right) ; \mathrm{c}$ ) os contribuintes do imposto de renda que pagam, creditam, empregam, remetem ou entregam recursos aos produtores, distribuidores ou intermediários no exterior, como rendimentos decorrentes da exploração de obras audiovisuais estrangeiras, podem beneficiar-se do abatimento de $70 \%$ do imposto devido ao investirem em co-produções de obras audiovisuais cinematográficas brasileiras de produção independente $\left(\operatorname{art.} 3^{\circ}\right)$.

A Lei do Audiovisual impõe um limite financeiro de R\$3 milhões, por projeto, para cada incentivo previsto nos artigos $1^{\circ}$ e $3^{\circ}$ desta lei, podendo esses incentivos ser utilizados concomitantemente.

\section{Lei Rouanet (Lei $\mathrm{n}^{\circ}$ 8.313, de} 23.12.1991): permite abater parcialmente do imposto de renda devido os valores destinados a doações ou a patrocínios de produção cinematográfica:

- pessoa jurídica: 30\% para patrocínio e $40 \%$ para doação - quando tributada com base no lucro real, a pessoa jurídica poderá abater as doações e patrocínios como despesa operacional;

- pessoa física: $60 \%$ para patrocínio e $80 \%$ para doação.

Vale ressaltar que o art. $6^{\circ}$ da Lei $n^{\circ}$ 9.532, de 10.12.1997, impõe um limite de isenção total de 4\% do imposto de renda devido, incluindo os incentivos da Lei Rouanet e da Lei do Audiovisual e as doações feitas aos Fundos dos Direitos da Criança e do Adolescente ${ }^{4}$.

Os mecanismos de incentivo existentes por meio de isenções fiscais apresentam falhas que desestimulam a auto-suficiência da atividade cinematográfica no Brasil. Primeiramente, o art. $1^{\circ}$ da Lei do Audiovisual permite abater integralmente o valor investido na aquisição de cotas de comercialização do imposto de renda 
devido, como também lançá-lo como despesa operacional, o que reduz o valor final do imposto a pagar. Na prática, esse benefício implica dupla dedução, ou seja, um abatimento de $125 \%$ do imposto de renda devido, o qual desestimula as empresas a aplicarem recursos próprios na atividade cinematográfica, orientando seus investimentos principalmente pelo estímulo fiscal. Por conseguinte, as empresas, ao invés de serem incentivadas a aplicar recursos próprios como meio de alavancar a atividade cinematográfica, tornam-se meras repassadoras de recursos públicos.

No que tange ao retorno financeiro da atividade cinematográfica no Brasil, o Estado, principal financiador de produções cinematográficas, por intermédio de renúncia de receitas, não participa da distribuição de eventual lucro que o filme venha a obter com a exibição. Se houver ganho, este é dividido entre a empresa produtora (proponente), os co-produtores (contribuintes relativos ao art. $3^{\circ}$ da Lei do Audiovisual) e os investidores (contribuintes de que trata o art. $1^{\circ}$ da Lei do Audiovisual). Além disso, o proponente, ao submeter seu projeto ao Ministério da Cultura, com o intuito de obter autorização para captação de recursos, não necessita apresentar, como um dos requisitos à aprovação, a viabilidade técnica e comercial. É de se estranhar a revogação da parte do art. $4^{\circ}$ da Lei do Audiovisual que elencava vários requisitos aos quais os projetos a serem beneficiados por incentivos fiscais deveriam submeter-se ${ }^{5}$.

Outra questão relacionada ao modelo de incentivos fiscais na área cultural adotado no Brasil é o fato de que o Estado delega o seu poder de impor diretrizes à política cultural às empresas que estão dispostas a "financiar" projetos culturais por meio de incentivos fiscais. Isso porque elas têm a liberdade de escolher o projeto cultural mais adequado à sua marca e imagem, utilizandose, na verdade, de recursos públicos por meio de renúncia de receitas tributárias. Como conseqüência, verifica-se que o financiamento, por meio de renúncias fiscais, de projetos na área cinematográfica é direcionado principalmente à produção. Isso porque, para as empresas financiadoras, em termos de estratégia de marketing, a produção garante visibilidade maior do nome do patrocinador. Como conseqüência, os distribuidores nacionais ficam em segundo plano em termos de financiamento, o que contribui para o chamado "gargalo" na cadeia produtiva, ou seja, uma quantidade expressiva de filmes produzidos, porém sem veiculação, assunto que será discutido em seguida.

\section{A remuneração entre os elos da cadeia produtiva}

A repartição das receitas de bilheteria entre os diferentes elos da cadeia dá-se de forma bastante desigual. Os maiores beneficiários são os distribuidores e exibidores, pois, além dos custos da produção, o produtor paga as despesas de comercialização, ou seja, anúncios de jornal, TV, cartazes e material de divulgação que são concedidos pelo distribuidor a título de adiantamento ${ }^{6}$. Logo que há o retorno em termos de bilheteria, esse adiantamento é devolvido à distribuidora. Sendo assim, as distribuidoras são as primeiras a receber os resultados da bilheteria, tanto no Brasil como no resto do mundo.

De acordo com o relatório Os tributos na cadeia econômica de exploração do mercado audiovisual nacional - Ancine, 2005, o distribuidor, no Brasil, investe nas despesas de comercialização, mas retém 100\% das receitas do produtor para recuperar esse investimento. Após os descontos tributários e a comissão de 
distribuição, o rendimento médio do produtor brasileiro por filme é de $\mathrm{R} \$ 1,45$ milhão.

No caso brasileiro, mediante a renúncia fiscal realizada com base no art. $3^{\circ}$ da Lei do Audiovisual, as majors não pagam os direitos dos filmes aos produtores, ou seja, adquirem os direitos de distribuição do filme, pois investem na produção de obras cinematográficas independentes por meio de incentivos fiscais. Com isso, as distribuidoras nacionais independentes ficam em desvantagem, pois não deixam de ter o encargo do pagamento dos direitos de distribuição dos filmes e não contam com as economias de escala permitidas pelas amplas redes de distribuição das majors. Além dos distribuidores, os grandes beneficiários são os exibidores, que participam de alto um filme, a distribuidora está prestando um serviço ao produtor cuja remuneração é, no caso de filme brasileiro, de aproximadamente $20 \%$ a $22,5 \%$ da renda de distribuição. Segue, na Tabela 3, a repartição, entre os elos da cadeia, da receita bruta de bilheteria, em termos percentuais.

Com isso, para conseguir novos recursos, o produtor recorre à captação em empresas por meio do incentivo fiscal. Neste contexto, conclui-se que as falhas da legislação de incentivos, a fragilidade do produtor diante do distribuidor e exibidor, agravada pela tributação em cascata, que será discutida adiante, contribuem para a perpetuação da dependência do produtor em relação aos incentivos fiscais, cuja perspectiva não é de diminuí-la.

Vale ressaltar que, quando se qualifica o elo produção como o mais frágil na

Tabela 3: A repartição da receita bruta de bilheteria entre os elos da cadeia

\begin{tabular}{l|l}
\hline Receita bruta de bilheteria (*) & $\mathbf{1 0 0 \%}$ \\
\hline Receita bruta do exibidor & $50 \%$ \\
\hline Receita bruta do distribuidor/produtor & $50 \%$ \\
\hline Comissão de distribuição & $20 \%$ a $22,5 \% * *$ sobre a receita do distribuidor/produtor \\
\hline Despesas de comercialização & $10 \% * * *$ até a total recuperação \\
\hline Receita bruta do produtor & $17,5 \%$ a $20 \%$ \\
\hline
\end{tabular}

(*) Não descontados os tributos: Cofins, PIS, CPMF e ISS.

(**) De acordo com dados do relatório Os tributos na cadeia econômica de exploração do mercado audiovisual nacional Ancine, 2005.

(***) Idem.

percentual das receitas de bilheteria, além da comercialização publicitária (mídia-tela) e da venda de comestíveis.

Sendo assim, o produtor é o último elo a ser remunerado na cadeia produtiva e com um percentual menor do que os demais, que, geralmente, não cobre os custos para iniciar-se uma nova produção. Segundo o relatório citado, ao distribuir cadeia produtiva, está-se levando em conta a baixa remuneração final do produtor em comparação com os demais elos, o que compromete, por sua vez, a capacidade de reinvestimento em novas produções. Como se verá no subtópico "A legislação de incentivo ao cinema", a legislação de incentivo beneficia primordialmente a produção em detrimento dos demais elos 
da cadeia, principalmente as empresas de distribuição de capital nacional. No entanto, essa situação de vulnerabilidade dos distribuidores nacionais não retira o atributo de fragilidade do setor produtivo. Isso porque, ao analisar-se a cadeia produtiva como um todo, leva-se em consideração não apenas as empresas de capital nacional envolvidas com a atividade cinematográfica, mas, também, as empresas estrangeiras, notadamente as representadas pelas majors, que detêm poder de mercado significativo, explicado, em parte, pela alta concentração desse segmento (vide Tabelas 1 e 2).

Por outro lado, deve-se enfatizar a necessidade de regulamentação da legislação de incentivos fiscais (explicitada na Conclusão deste artigo), de forma a contemplar os demais elos da cadeia (por exemplo, distribuidores e exibidores nacionais). Isso permitirá, além do fortalecimento desses segmentos, diminuir a vulnerabilidade de produtores nacionais em relação às dificuldades de acesso às redes de distribuição e exibição.

Ao contrário do mercado americano, as receitas de bilheteria no Brasil representam a maior fonte de remuneração dos elos da cadeia produtiva, visto que o mercado de vídeo e as vendas para a televisão são pouco significativos. Por outro lado, há o agravante da redução significativa do número de salas de exibição ocorrida entre 1980 e 2000 . Segundo o relatório Os tributos na cadeia econômica de exploração do mercado audiovisual nacional-Ancine, 2005, no Brasil, durante a década de 1970, o número de ingressos vendidos, ao ano, oscilava entre 200 milhões e 250 milhões, enquanto, na década de 1990, foi em torno de 70 milhões de ingressos. Atualmente, o País conta com cerca de 2.000 salas de exibição e já ultrapassou o patamar de 100 milhões de ingressos vendidos anualmente ${ }^{7}$.
A queda da freqüência ao cinema começa em meados da década de 1980, atingindo, sobretudo, as camadas populares do País, tendo em vista que os cinemas que se fecham estão localizados, principalmente, nas pequenas cidades do interior, nos bairros pobres e na periferia das grandes cidades. De acordo com o citado relatório, a redução significativa no número de salas e na quantidade de expectadores deve-se ao aumento do custo do ingresso, à queda da renda do trabalhador brasileiro, à política de contenção de cópias por parte das distribuidoras majors norte-americanas, o que tem provocado o fechamento de salas de pequenos circuitos e ao surgimento de outros segmentos de mercado de exibição (novas mídias, como vídeo doméstico e DVD, além das TVs por assinatura).

\section{Tributação em cascata da cadeia produtiva}

Com relação à estrutura tributária do setor $^{8}$, há incidência de tributos municipais e federais sobre a venda de ingressos, como é o caso do Imposto sobre Serviços de Qualquer Natureza (ISS), com alíquotas variáveis entre $2 \%$ e $5 \%{ }^{9}$, conforme a legislação específica do município. O ISS incide sobre o preço do serviço prestado, ou seja, no momento da venda dos ingressos, e o seu recolhimento é efetivado no começo do mês subseqüente ao da ocorrência do fato gerador. Há incidência de outros tributos municipais que, embora não incidam diretamente sobre a receita advinda da venda dos ingressos, oneram o exibidor, tais como: o Imposto Predial e Territorial Urbano (IPTU), a Taxa de Licença para Estabelecimento, a Taxa de Autorização de Publicidade e de painéis publicitários (fachadas) e as taxas de incêndio. Em 
âmbito federal, incidem diretamente sobre o faturamento decorrente do valor cobrado pelo ingresso vendido a Contribuição para o Financiamento da Seguridade Social (Cofins), à alíquota de 7,6\%, e a Contribuição para o Programa de Integração Social (PIS), à alíquota de 1,65\%. Esta incidência é compensada, parcialmente, conforme o nível de despesas dedutíveis apuradas no período tributado, antes do seu efetivo pagamento.

Os direitos autorais, embora não sejam tributos, incidem sobre o valor do ingresso e decorrem da execução pública de fonogramas inseridos nas obras cinematográficas. A alíquota de 2,5\% sobre a renda bruta é recolhida mensalmente pelo Escritório Central de Arrecadação de Direitos Autorais (Ecad), órgão responsável pela arrecadação dos valores referentes aos direitos autorais e posterior distribuição aos detentores desse direito, conforme a Lei $\mathrm{n}^{\circ}$ 9.610/98. Embora a cobrança esteja sendo contestada judicialmente por diversas empresas exibidoras, essa obrigação financeira onera da mesma forma que qualquer tributo.

Ademais, outros tributos, como o Imposto sobre Importação de Produtos Estrangeiros (II $)^{10}$, Imposto sobre Produtos Industrializados (IPI) e Imposto sobre Operações Relativas à Circulação de Mercadorias e Prestação de Serviços de Transporte Interestadual e Intermunicipal e de Comunicação (ICMS), recaem de forma indireta na atividade de exibição cinematográfica, cujos mais importantes são aqueles incidentes na aquisição de equipamentos importados. As alíquotas aplicadas não diferenciam os equipamentos de uso profissional daqueles que têm como finalidade o uso doméstico. Há também as incidências de Imposto sobre a Renda (IR) e de Contribuição Social sobre o
Lucro Líquido (CSLL), cujas alíquotas dependem do regime contábil de cada empresa, assim como de seus resultados.

Com relação ao segmento da distribuição, verifica-se a tributação em cascata, da seguinte forma: o exibidor do filme, cuja receita cabe aos três setores (exibidor/ distribuidor/produtor), deverá arcar com o pagamento da Contribuição Provisória sobre Movimentação ou Transmissão de Valores e de Créditos e Direitos de

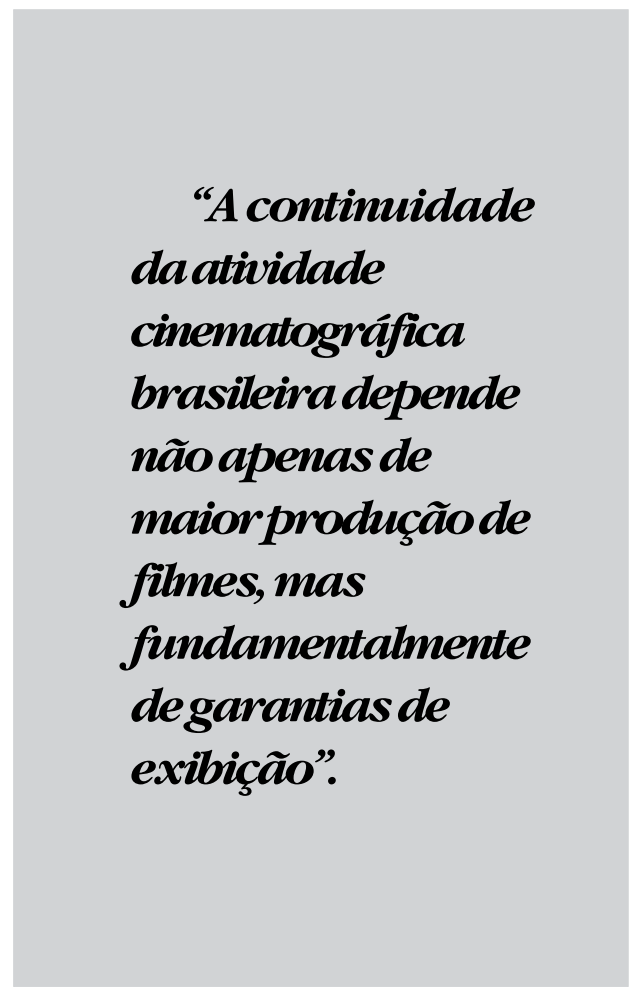

Natureza Financeira (CPMF). Além disso, por se tratar de serviço ao distribuidor, há a retenção de $5 \%$ do total da receita bruta a título de ISS. Em razão da legislação, o exibidor é obrigado a recolher ainda o PIS e a Cofins sobre o total da receita bruta e não apenas sobre a parte que lhe cabe. Ao repassar a receita ao distribuidor, haverá nova incidência dos mesmos tributos, ou seja, Cofins, PIS, CPMF e ISS sobre a 
remuneração do distribuidor. Ademais, haverá a cobrança da Contribuição para o Desenvolvimento da Indústria Cinematográfica Nacional (Condecine) e, no caso das distribuidoras estrangeiras, imposto de renda sobre a remessa para o exterior de rendimentos decorrentes de exploração de filmes estrangeiros.

Atualmente, no Brasil, são lançados cerca de 30 filmes nacionais e 200 estrangeiros no mercado de salas. Os filmes brasileiros detêm apenas 15\% do público que freqüenta as salas de exibição. Sendo assim, além de o produtor deter uma parcela pequena do mercado, os seus rendimentos também sofrem a tributação em cascata, pois são taxados novamente pelos tributos: Cofins, PIS e CPMF ${ }^{11}$.

\section{Legislação de comunicação eletrônica de massa e a parceria entre TV e cinema}

A discussão a respeito da viabilidade da atividade cinematográfica no Brasil como atividade econômica auto-sustentável não pode passar ao largo da parceria com o meio de comunicação hegemônico no País: a televisão aberta. A continuidade da atividade cinematográfica brasileira depende não apenas de maior produção de filmes, mas fundamentalmente de garantias de exibição. Com isso, os meios de alavancagem da produção cinematográfica no Brasil não se limitam à disponibilidade de recursos, sejam públicos ou privados, mas também da existência de regras regulatórias que permitam o acesso da produção nacional independente (vídeo e cinema) aos meios de comunicação eletrônica de massa, por meio, por exemplo, de cotas de exibição e produção associada, prática difundida em países desenvolvidos ${ }^{12}$.
O governo federal, pelo Decreto $\mathrm{s} / \mathrm{n}^{\circ}$, de 26 de abril de 2005, alterado pelo Decreto s/n ${ }^{\circ}$, de 18 de agosto de 2005, criou um grupo de trabalho interministerial com a finalidade de elaborar um anteprojeto de lei, que visa à regulamentação dos artigos 221 e 222 da Constituição Federal, relativos à comunicação social e à organização e exploração dos serviços de comunicação social eletrônica. Uma das justificativas é a caducidade da legislação atual em face do surgimento de novas mídias e do processo de convergência tecnológica, ou seja, a possibilidade do conteúdo de comunicação social ser transmitido por vários meios de distribuição, como fibra ótica, satélite, cabo, microondas, entre outros. Nesse contexto, há a necessidade de um marco regulatório capaz de abarcar vários meios de geração de imagens, como a televisão, a internet, os jogos eletrônicos e a telefonia celular.

Esta será a oportunidade também de discutir formas de fortalecer um dos princípios constitucionais, ou seja, a promoção da cultura nacional e regional e o estímulo à produção independente prescrito no art. 221 da Constituição Federal. Pode-se dizer que uma das características marcantes da sociedade brasileira é o fato de estar fundada na diversidade cultural, explicada, em grande medida, pela variedade de origens étnicas e religiosas. Nesse sentido, o reconhecimento da legitimidade dessa diversidade representa um primeiro passo para a intervenção em termos de política de Estado. Um dos caminhos seria a criação de regras regulatórias que respaldassem uma parceria efetiva entre a TV e o cinema porque o cinema, apesar de não ser a única, é fonte riquíssima de formação de identidades culturais.

Ao contrário dos EUA e da Europa, onde a indústria cinematográfica representa a matriz cultural básica da cadeia produtiva 
do audiovisual, no Brasil a televisão e o cinema não se complementam como atividades comerciais. Isso se deve ao fato de que há diferenças acentuadas em termos tecnológicos, organizacionais e competitivos entre os segmentos da indústria de produtos audiovisuais.

A televisão brasileira desenvolveu uma estrutura original que compatibiliza propriedade comercial com diferentes formas de intervenção estatal. O Estado brasileiro defendeu suas fronteiras nacionais contra a influência do vídeo estrangeiro, por meio do controle da porcentagem de programas nacionais exibidos pelas emissoras, do reforço à exclusividade do capital nacional nas empresas de comunicação, da imposição da língua portuguesa como língua oficial e única e da definição de sistemas tecnológicos próprios, como o PAL-M, ou seja, uma combinação do sistema de cor alemão, PAL, com o sistema norte-americano NTSC. Ademais, a interferência do governo dá-se também por meio da concessão pública de canais, de empréstimos concedidos por bancos oficiais, dos anúncios publicitários de empresas oficiais e da censura, que vigorou até 1980 para o jornalismo e até 1988 para as novelas, quando foi promulgada a Constituição, que a aboliu ${ }^{13}$.

A expansão da indústria da televisão brasileira compreende o período entre 1970 e $1989^{14}$. A Rede Globo praticamente exerceu o monopólio durante essa fase, com uma grade de programação baseada no "sanduíche" novelas e noticiário. As novelas tornaram-se o produto principal dessa indústria, inclusive de exportação para vários países em todos os continentes. Esse período, chamado de "consolidação" da indústria, caracterizou-se por intensa interferência política e econômica do regime militar, o que não inibiu o desen- volvimento de mercado de consumo, tornando a televisão uma atividade econômica lucrativa, intrinsecamente ligada ao desenvolvimento dos anos do "milagre econômico", o que implicou a convivência de um mercado consumidor desenvolvido, ou seja, a venda de produtos de multinacionais por meio da propaganda, com a pobreza e a desigualdade.

Atualmente, como forma de obter ganhos de escala, as emissoras verticalizam o processo de produção e veiculação de programas, ou seja, a maior parte da produção de conteúdo é realizada por um núcleo de produção, que pertence ao mesmo grupo empresarial e realiza o papel de programadora. Por conseguinte, há a limitação de aquisição de produtos audiovisuais produzidos por produtoras independentes, inclusive filmes nacionais, devido aos altos custos ${ }^{15}$.

\section{Conclusão}

Não obstante o poder público conceder incentivos fiscais para alavancar a atividade cinematográfica e, de certa forma, criar aberrações como o art. $1^{\circ} \mathrm{da}$ Lei do Audiovisual, que prevê abatimento de 125\% do imposto de renda devido, ao mesmo tempo há a penalização do setor por meio de uma estrutura tributária excessiva e distorcida. Tendo em vista que a empresa produtora é o último elo da cadeia produtiva a ser remunerado, a tributação em cascata sobretaxa de forma mais acentuada os rendimentos do produtor. Ao se procurar corrigir essas distorções, tornando a estrutura tributária mais racional, as diferenças nas margens de ganho em relação aos demais elos diminuirão, tornando mais eqüitativo os encargos tributários entre os segmentos do setor, de forma a proporcionar maiores 
possibilidades de auto-suficiência do produtor independente.

Nesse sentido, a legislação vigente, seja tributária, seja com relação aos incentivos, pode ser aprimorada, corrigindo essas distorções. Especificamente, pode-se propor a diminuição dos limites de isenção concedida pelo art. $1^{\circ}$ da Lei do Audiovisual às empresas que, muitas vezes, não têm compromisso com o produto final e visam unicamente ao incentivo fiscal e incluir outros segmentos integrantes do setor audiovisual, como a televisão, por meio do art. $3^{\circ}$, explicitado adiante.

Recentemente, resgatou-se a discussão, primeiramente proposta no projeto da Agência Nacional do Cinema e Audiovisual (Ancinav), a respeito da extensão do benefício fiscal previsto no art. $3^{\circ}$ da Lei do Audiovisual para a televisão. $\mathrm{O}$ anteprojeto de lei de criação da Ancinav previa o abatimento de $70 \%$ do imposto de renda devido sobre rendimentos decorrentes, não apenas sobre exploração, aquisição ou importação de obras audiovisuais estrangeiras, como consta da Lei do Audiovisual, mas também sobre a transmissão, por meio de televisão ou de qualquer outro meio, de obra audiovisual. Esse abatimento, de acordo com o anteprojeto de lei, está condicionado à produção de obras cinematográficas brasileiras de longa metragem de produção independente e à co-produção de obras cinematográficas e vídeofonográficas brasileiras de produção independente de curta, média e longa metragem, documentários, telefilmes e minisséries. Isso permitiria uma aproximação maior entre a TV e o cinema, o que possibilitaria a ampliação da grade de programação televisiva para essas obras.

Ademais, devem ser propostas outras alterações na legislação de incentivos vigente. Diante das falhas na legislação de incentivo já elencadas, propõem-se alguns condicionantes para que a captação de incentivos fiscais seja autorizada pelo Ministério da Cultura, ou seja, requisitos aos quais os projetos devem ser submetidos, como, por exemplo, viabilidade técnica e comercial para filmes de alto custo, o que contribuiria para a integração entre produtores, distribuidores, exibidores e televisão. Além de reduzir o período de tempo da produção para atender às expectativas dos investidores, diminuiriam-se os riscos de obras serem financiadas sem garantias de veiculação. Com isso, devem-se resgatar, do art. $4^{\circ}$ da Lei do Audiovisual os requisitos anteriormente previstos, que foram revogados pela Lei $\mathrm{n}^{\circ} 10.454$, de 13.5.2002, e adotar um fator de risco para filmes de alto custo, ou seja, que parte dos retornos financeiros dessas produções retornem ao Estado como forma de financiamento para futuros projetos.

Por outro lado, deve-se ter em mente que a viabilidade comercial de determinado projeto terá maiores garantias se a legislação de incentivo contemplar, em termos efetivos, todos os elos da cadeia produtiva. Percebe-se que a forma pela qual a legislação de incentivos, notadamente a Lei do Audiovisual, é atualmente utilizada não contempla uma estratégia de intervenção sobre todos os elos da dessa cadeia. Apesar de o art. $1^{\circ}$ da Lei do Audiovisual prever benefícios fiscais para projetos de distribuição, exibição e infraestrutura técnica apresentados por empresas de capital nacional, ainda não foi elaborada pela Ancine instrução normativa específica para esses projetos, conforme se verifica no Manual do produtor-Cinema e audiovisual - Leis de incentivo (Ancine). Isso contribui, além dos fatores apontados anteriormente, para que o setor de 
produção seja mais favorecido por recursos incentivados, em detrimento dos demais.

Convencionou-se dizer que o gargalo do setor cinematográfico no Brasil é a distribuição. No entanto, deve-se atentar para o baixo poder aquisitivo da população que também representa um ponto de estrangulamento importante do setor. Hoje, no País, o preço médio do ingresso é de $\mathrm{R} \$ 7,00$, o que contribui também, além de outros fatores elencados no subtópico "A remuneração entre os elos da cadeia produtiva", para o baixo nível de venda de ingressos per capita, que, atualmente, está em meio ingresso por ano ${ }^{16}$.

Tais circunstâncias apontam para a indispensável integração entre cinema e televisão. As emissoras de televisão aberta podem exercer o papel de ampliar o acesso do público a produções cinematográficas, facilitado, por sua vez, pelo uso da tecnologia digital, que permite não apenas reduzir os custos de produção, devido à substituição do celulóide, como também compatibilizar vários meios de distribuição de conteúdo audiovisual . Além disso, a exibição de filmes nacionais pela televisão pode representar também grande atrativo em audiência e, por conseqüência, maiores retornos comerciais ${ }^{17}$.

No entanto, deve-se ressaltar que há vários fatores que dificultam uma efetiva parceria entre cinema e TV. Primeiramente porque, visto que a televisão brasileira é predominantemente de caráter comercial e está alicerçada sob bases industriais, qualquer interferência em sua grade de programação, que faça que ela fuja de determinado modelo compatível com o mercado, pode resultar no comprometimento da audiência e, por conseguinte, grandes prejuízos financeiros e a inviabilidade de seus negócios. O esforço de conquistar determinado nível de audiência implica rotinas de análise e de pesquisas quantitativas e qualitativas (como o diagnóstico de gostos, expectativas e reações dos telespectadores), que não somente monitoram a flutuação da audiência, fornecendo dados que definem padrões de medida para o preço dos anúncios, mas também atuam como direcionadores na definição de linhas de programação. Por conseqüência, qualquer medida de caráter regulatório que tenha por fim garantir a participação de filmes brasileiros na programação televisiva deparar-se-á com resistências das próprias radiodifusoras, visto que intervirá no processo da disputa acirrada entre as emissoras por audiência.

Essa resistência é fortalecida pela comunhão de interesses entre as radiodifusoras e a classe política. Isso porque, mesmo com o fim do regime militar, o sistema de concessão e controle das emissoras de televisão continuou submetido a ingerências políticas, passando do Executivo para o Legislativo. Políticos, num contexto de barganha política, tornaram-se concessionários de emissoras de televisão.

A cumplicidade entre políticos e radiodifusoras explica, em boa parte, o adiamento, por parte do Legislativo, da regulamentação dos arts. 221 e 222 da Constituição Federal, relativos à comunicação social. A regulamentação permitiria não apenas a atualização da legislação no tocante ao surgimento das novas tecnologias de comunicação eletrônica, como também a redefinição de critérios para a concessão de canais de televisão, o papel de uma futura agência reguladora e as formas de controle e avaliação das emissoras no que se refere, por exemplo, a conteúdo da programação ${ }^{18}$ e à propriedade cruzada dos meios de comunicação.

A alta concentração do mercado televisivo privado no Brasil verifica-se pela 
presença de apenas seis redes nacionais (Globo, SBT, Record, Bandeirantes, Rede TV! e CNT), das quais somente a Globo detém aproximadamente $50 \%$ da audiência. Essa concentração é agravada visto que grande parte da população nem sequer tem poder aquisitivo para ter acesso a outras fontes de informação, tais como mídia impressa, TV por assinatura e internet. Tal fato se reflete em grande concentração das verbas publicitárias em mídia eletrônica, especialmente em TV, em detrimento de investimentos nas demais modalidades de mídia. Além disso, constatam-se uma padronização da programação e uma sobreposição de programas entre as principais geradoras, caracterizadas pela combinação de novelas, programas infantis, noticiários, programas de auditório e os chamados "enlatados". Por conseqüência, a ausência de regulação compromete a pluralidade e diversificação da programação.

Diante disso, o que se espera dos debates sobre uma Lei Geral de Comunicação de Massa é que haja efetiva participação dos vários segmentos da sociedade e que os interesses de uma mídia altamente concentrada, como é o caso da brasileira, não se sobreponham a princípios legitimados, como a valorização da cultura nacional e a importância da garantia de diversidade de informações, de opiniões e, por conseqüência, de programações. Nesse contexto, a sustentabilidade da atividade cinematográfica brasileira não pode prescindir da parceria cinema/TV, que deve ser vista não apenas como um meio de comunicação industrial consolidado, ou seja, a televisão, subsidiar uma atividade ainda considerada artesanal e economicamente frágil, mas, sim, a garantia de acesso da população a outras formas de linguagem da produção audiovisual e da pluralidade da programação. Isso representará o fortalecimento de princípios de política pública, como também a porta de entrada ao mercado hegemônico da produção e transmissão de produtos audiovisuais.

(Artigo recebido em outubro de 2005. Versão final em março de 2006)

\section{Notas}

* Gostaria de agradecer a algumas pessoas que, direta ou indiretamente, contribuíram para este trabalho: Marcelo de Matos Ramos, Mário Sérgio Gordilho, Cláudia Santos Viegas, Monica Szerman, Luís Henrique D’Andrea, Bruno Queiroz Cunha, Marcelo Fiuza Lima, Samantha Salomoni, Iracema Fujiyama e Carlos Frederico Alverga.

${ }^{1}$ Segundo o relatório Diagnóstico governamental da cadeia produtiva do audiovisual-MinC (2000).

${ }^{2}$ De acordo com Vogel (2001), que faz uma análise da indústria americana de entretenimento, inclusive o cinema, os filmes apresentam variância elevada em termos de lucratividade. Ao escolher uma amostra de dez filmes, na média, seis ou sete podem ser caracterizados como não lucrativos, dois ou três são produções que equilibram custos e retornos e apenas um filme é bem-sucedido, capaz de cobrir os prejuízos das demais produções e viabilizar o cinema enquanto atividade econômica.

${ }^{3}$ Custos irrecuperáveis: despesas com atores, equipe técnica, publicidade, entre outros.

${ }^{4}$ De acordo com dados da Ancine, a captação dos incentivos fiscais em projetos audiovisuais da Lei do Audiovisual e da Lei Rouanet no exercício de 2004 foi, respectivamente, de R \$ 85,5 milhões e R\$27,4 milhões. 
${ }^{5}$ De acordo com o Relatório de Auditoria do Tribunal de Contas da União relativo ao Processo $\mathrm{n}^{\circ}$ 005.628/2004-0, uma das formas de minimizar o alto índice de filmes não veiculados é o aprimoramento de critérios para a aprovação de projetos, como as análises de viabilidade técnica, comercial, desempenho anterior da empresa produtora com veiculação, sucesso de público, ocorrências na aplicação de recursos públicos, entre outros. Segundo o art. 14 da IN/Ancine nº 22/2003, as análises que precedem a aprovação dos projetos levam em conta somente a capacidade empresarial do proponente, a compatibilidade de custos do roteiro com o orçamento, a regularidade fiscal, previdenciária e no Cadastro de Inadimplentes (Cadin) e a regularidade com as obrigações decorrentes da utilização de leis de incentivo. No que tange à capacidade empresarial, a verificação baseia-se, segundo a IN/Ancine $n^{\circ}$ 23/2004, somente na duração em minutos do conjunto das obras audiovisuais do proponente, no intuito de estabelecer limites financeiros de utilização dos mecanismos de incentivo fiscal.

${ }^{6}$ Um caso que se tornou notório em termos de diferenças de remuneração entre os elos da cadeia produtiva é o que ocorreu com Fernando Meirelles, produtor de Cidade de Deus, que assinou um contrato com a major Miramax mediante o qual cedeu à empresa o direito de distribuição no Brasil e na América. Em troca, a Miramax garantiu o retorno de dois terços investidos na produção pela O2 Filmes, produtora que tem como um dos sócios o próprio diretor. No entanto, as receitas geradas pelo filme superaram significativamente os $\mathrm{R} \$ 5,5$ milhões financiados inicialmente pela $\mathrm{O} 2$ Filmes.

${ }^{7}$ Com relação ao mercado mundial de salas de exibição, o Brasil ocupa o $12^{\circ}$ lugar em público, o $45^{\circ}$ lugar em número de ingressos per capita e o $52^{\circ}$ lugar na relação número de habitantes por sala de exibição (Fonte: Filme B).

${ }^{8}$ Ver o relatório Os tributos na cadeia econômica de exploração do mercado audiovisual nacional, no segmento salas de exibição, infra-estrutura e TV por assinatura - Ancine (2005).

${ }^{9}$ Atualmente, as alíquotas mínima e máxima fixadas para o ISS são de $2 \%$ e $5 \%$; segundo a Emenda Constitucional n 37/02 e a Lei Complementar no 116/03, respectivamente.

${ }^{10}$ Há incidência de PIS e Cofins na importação, cuja base de cálculo de ambos é o valor aduaneiro, entendido como o valor que serve de base para o cálculo do II, acrescido do valor do ICMS incidente no desembaraço aduaneiro e do valor das próprias contribuições, na hipótese de entrada de bens estrangeiros no território nacional (art. $7^{\circ}$ da Lei n ${ }^{\circ} 10.865$, de 30.4.2004).

${ }^{11}$ Ver o relatório Os tributos na cadeia econômica de exploração do mercado audiovisual nacional, no segmento salas de exibição, infra-estrutura e TV por assinatura - Ancine (2005).

${ }^{12}$ A título de exemplo, a França conta com uma legislação protetora no que concerne ao mercado audiovisual, o que implica, entre várias outras medidas, a obrigação de os canais de televisão, sejam públicos ou privados, subordinarem-se à cota de tela e investirem na produção nacional e européia. Com relação à cota de tela, o Decreto no 90-66, de 17.1.1990, alterado pelo Decreto no 2004-1481, de 23.12.2004, prescreve obrigações de difusão de obras cinematográficas e obras audiovisuais européias e de expressão original francesa. Especificamente, o art. $7^{\circ}$ dispõe que as emissoras de televisão devem dedicar ao menos, dentro do número total de filmes de longa metragem transmitidos e retransmitidos, $60 \%$ a filmes europeus e $40 \%$ a filmes de expressão original francesa, em horários de grande audiência, ou seja, entre $20 \mathrm{~h} 30$ e $22 \mathrm{~h} 30$ (legislação disponível no site <http:// www.legifrance.gouv.fr $>$. Acesso em: 15.8.2005).

${ }^{13}$ Ver Esther Hamburguer, O Brasil antenado, p. 22.

${ }^{14}$ Idem, p. 30.

${ }^{15}$ Segundo Takashi et al. (2002), ao adquirirem produções independentes, as emissoras tomam por base o custo de produção de suas novelas (cerca de US\$ 80 mil por capítulo) ou o custo dos filmes e desenhos importados (entre US\$ 5 mil e US\$ 50 mil). Com isso, as emissoras não se dispõem a pagar mais do que US $\$ 50$ mil pelos direitos de um filme nacional, que, ao ser produzido no padrão exigido pelas emissoras, custa em torno de US\$100 mil. Assim, o modelo comercial 
adotado baseia-se na comercialização de grandes blocos na grade de programação para a transmissão desses conteúdos, restando para a produtora todo o custo de produção e de divulgação, além do risco financeiro pela operação.

${ }^{16}$ Relatório Os tributos na cadeia econômica de exploração do mercado audiovisual nacional, no segmento salas de exibição, infra-estrutura e TV por assinatura-Ancine, p. 6.

${ }^{17}$ A título de exemplo, a exibição do filme Carandiru, na Rede Globo, em "Tela Quente", em 6.6.2005, resultou no maior índice de audiência verificado na sessão, em três semanas. A prévia da audiência aferida pelo Ibope para a Grande São Paulo resultou em 42 pontos (cada ponto corresponde a 80 mil domicílios) e uma participação de $57 \%$ de todos os televisores ligados no horário. Comparandose com a semana passada, o filme americano Tudo para ficar com ela, exibido no mesmo horário, rendeu 35 pontos de média. Na semana anterior, com outro filme americano, Não é mais um besteirol americano, o índice fora de 38 pontos. Notícia disponível em < http:/ /www.paytv.com.br>. Acesso em: 7.6.2005.

${ }^{18}$ Vera Nusdeo Lopes, citada por Esther Hamburguer (2005), p.37, compara a legislação brasileira sobre a matéria com a de outros países, como a Inglaterra e os Estados Unidos, nos quais as comissões técnicas, cujos procedimentos são abertos ao público, prevalecem na definição das empresas concessionárias e a sobreposição da produção e emissão de programas é limitada, o que força a uma certa abertura e diversidade do mercado.

\section{Referências bibliográficas}

AnCine. Manual do Produtor - Leis de incentivo - Cinema e audiovisual. Rio de Janeiro: 2005. . Tributos na cadeia econômica de exploração do mercado audiovisual nacional, no segmento salas de exibição, infra-estrutura e TV por assinatura. Rio de Janeiro: 2005.

Cesnik, Fábio S. Guia do incentivo à cultura. Barueri: Manole, 2002.

Debande, Olivier. The European audiovisual industry: an overview. Luxembourg: EIB Sector Papers, 2001.

Giansante, Moacir et al. Cadeia de valor - Projeto Sistema Brasileiro de Televisão Digital - Modelo de Implantação OS40539. Campinas: CPqD, 2004.

Hamburguer, Esther. O Brasil antenado - A sociedade da novela. Rio de Janeiro: Jorge Zahar, 2005.

Moisés, José A.; Lima, Verônica. Diagnóstico governamental da cadeia produtiva do audiovisual. Brasília: MinC, 2000.

SCHWARZ, Antoine. La production audiovisuelle française et son financement. Paris: Ministère de la Culture et de la Communication, 2003.

Silva, Frederico A. B. Financiamento cultural: situação atual e questões para reflexão. Boletim de Políticas Sociais - Acompanbamento e Análise, Rio de Janeiro, n. 8, p. 141-147, fev., 2004.

Tome, Takashi et al. Modelo de implantação da TV digital no Brasil. Campinas: CPqD, 2002. Vogel, Harold L. Entertainment industry economics. Cambridge: Cambridge University Press, 2004. 


\section{Resumo - Resumen - Abstract}

\section{Caminhos da sustentabilidade para o cinema brasileiro \\ Maria Cristina Attayde}

$\mathrm{O}$ artigo pretende mostrar as dificuldades de sustentabilidade da atividade cinematográfica brasileira. Com base na análise da cadeia produtiva, na estrutura tributária e nas falhas da legislação de incentivo fiscal, propõe-se a existência de um ciclo vicioso de dependência aos incentivos fiscais. Tendo em vista as dificuldades de acesso a salas de cinema, devido, entre outros fatores, ao baixo poder aquisitivo da população e à concentração geográfica de cinemas nas grandes cidades, propõe-se uma parceria efetiva entre cinema e televisão, facilitada pela tecnologia digital. Isso implicará alterações na legislação atual, bem como a criação de regras regulatórias, como forma de ampliar o acesso de filmes nacionais à grade de programação televisiva e também de viabilizar, em termos industriais, essa atividade econômica.

Palavras-chave: cinema, parceria, televisão

\section{Caminos hacia la sustentabilidad del cinema brasileño}

Maria Cristina Attayde

El artículo intenta mostrar las dificultades de sustentabilidad de la actividad cinematográfica brasilera. Analizando la cadena productiva, la estructura tributaria y las imperfecciones de la legislación de incentivo fiscal, el artículo propone mostrar la existencia de un ciclo vicioso de dependencia a los incentivos fiscales. Debido el acceso difícil a las salas de cine, explicado por el poder de compra bajo de la población y la concentración geográfica de salas de cine en las ciudades grandes, el artículo propone una sociedad eficaz entre cinema y televisión, facilitada por la tecnología digital. Eso implicará alteraciones en la legislación actual, así como la creación de reglas regulatorias como forma de insertar las películas nacionales a la programación televisiva, además de tornar viable, en condiciones industriales, esa actividad económica.

Palabras clave: cinema, sociedad y televisión

\section{Paving the way to the sustainability of the Brazilian cinema}

\section{Maria Cristina Attayde}

The article intends to present the Brazilian cinema-related industry current difficulties of sustainability. By analysing its productive chain, the tax burden and the flaws in the tax incentive law, the article demonstrates a vicious cycle of dependence to the fiscal incentives. Due to difficult access to screening rooms, explained by the population's low purchasing power and the geographical concentration of movies in large cities, the article proposes an effective partnership between the cinema-related industry and the television, facilitated by digital technology. This implies alterations in the current legislation, as well as the creation of regulation rules, aiming to the inclusion of national films in the television programming and to enable the viability of this industry.

Key words: cinema, partnership, television

\section{Maria Cristina Attayde}

Economista e Especialista em Políticas Públicas e Gestão Governamental, atua hoje no Ministério da Fazenda. Contato: <maria.attayde@fazenda.gov.br> 